INTERNATIONAL JOURNAL OF SCIENTIFIC RESEARCH

COMPARATIVE STUDY OF PRE-CAESAREAN VAGINAL WASH WITH 5\% POVIDONE - IODINE SOLUTION VERSUS NO WASH IN PREVENTING POSTOPERATIVE INFECTION.

\title{
Obstetrics and Gynaecology
}

\begin{tabular}{ll}
$\begin{array}{l}\text { Dr. Sonali } \\
\text { Deshpande }\end{array}$ & Academic Professor, Department of OBGY, GMCH, Aurangabad. \\
\hline $\begin{array}{l}\text { Dr. Shrinivas } \\
\text { Gadappa }\end{array}$ & Professor \& Head, Department of OBGY, GMCH, Aurangabad.
\end{tabular}

Dr Dhanashree Lahane*

\section{Dr. Sandeep Mannikatti} \begin{abstract}
Objective: To evaluate the efficacy of pre-cesarean vaginal wash using 5\% Povidone Iodine solution on rate of post-cesarean section (CS) surgical site infection and compared with No swabbing.

Method: A Prospective Randomized controlled Trial was conducted in department of Obstetrics and Gynecology in Government medical college, Aurangabad. In interventional group, vaginal swabbing with a gauze pieces impregnated with 5\% Povidone Iodine solution was done for 30 seconds. The swabbing of vagina was not performed in cases assigned to control group, however the standard surgical preparation of abdomen was done in a usual manner for both group. All subject received prophylactic antibiotic cover. Collected data was complied in pre-designed proforma and analysis was done using SPSS 15.

Result: The risk of post operative fever and wound infection was significantly reduced in interventional group. No measure difference was noted in seroma and composite wound infection. Also less duration of hospital stay in interventional group was noted. No adverse effect of use of Povidone iodine was reported in the interventional group.

Conclusion: Vaginal swabbing with 5\% Povidone-iodine pre- LSCS is inexpensive and simple intervention even for low resource setting to decrease surgical site infection.
\end{abstract}

\section{KEYWORDS}

post operative infection, vaginal swabbing, caesarean section, seroma, composite wound infection.

\section{INTRODUCTION:}

Cesarean delivery is one of the most common surgical procedures performed by obstetricians. Infectious morbidity after cesarean delivery can have a tremendous impact on the postpartum woman's return to normal function and her ability to care for her baby. Despite the widespread use of prophylactic antibiotics, postoperative infectious morbidity still complicates cesarean deliveries. Endometritis, an infection of the uterus in the postpartum period, can complicate the postoperative course of a cesarean delivery $6 \%$ to $27 \%$ of the time ${ }^{1,2]}$. Cesarean delivery is increasing, particularly in the developed world. Postoperative infectious morbidity after cesarean delivery impacts the woman's return to normal function and potentially her bonding with the newborn. It can also cause major medical problems and squeale. Finding an easy, inexpensive method to reduce this risk could have major public health impact in both developed and developing countries ${ }^{[3]}$. Postpartum endometritis is an infection of the endometrial lining of the uterus clinically diagnosed by fever and uterine tenderness. Haas DM et al suggested a rate of wound infection of 97 per 1000 and 68 per 1000 for emergency and elective caesarean section, respectively; for endometritis the rates were 184 per 1000 versus 39 per $1000[3]$. Other risk factors for endometritis are chorioamnionitis, prolonged labor, prolonged rupture of membranes and vaginal colonization with Group B Streptococcus. Some complications of endometritis include prolonged hospital stay, sepsis, peritonitis and intra pelvic abscess. Surgical site infections are infections of the incision, organ or space after a procedure and are responsible for infections in patients undergoing surgery. This complication is about 10 times more common when compared with vaginal delivery and can lead to sepsis. ${ }^{[4,5]}$

Post cesarean infectious morbidity is caused by ascending the causative bacteria from the vagina and cervical canal; through haematogenous spread, to infect edges of the incised uterus ${ }^{[3]}$. Presence of the causative bacteria in the vagina is known to cause resistance against antibiotic therapy. So, even after receiving preoperative prophylactic antibiotics the vaginal lumen is found to be colonized with antibiotic-resistant bacteria and the rate of post cesarean infections remains a problem.[ 6]Current practices endorsed by WHO to reduce the incidence of infectious morbidity after cesarean section include pre-operative antibiotics and pre-operative skin cleansing with chlorhexidine skin preparation. Chlorhexidine and povidone-iodine are chemical antiseptics that reduces bacteria found on the skin. Additionally, vaginal scrub with $4 \%$ chlorhexidine gluconate and $10 \%$ povidone-iodine antiseptic solution immediately prior to cesarean section has been embraced into some practices as a means to decrease infectious morbidity. There is abundant literature showing preoperative vaginal swabbing prior to hysterectomy has been shown to decrease vaginal surgical site antisepsis; however research on its use prior to cesarean section is limited ${ }^{[6]}$

In our institute, the incidence of caesarean section is around $27 \%{ }^{[7]}$ Practicing clinical methods in order to decrease the infectious morbidity of cesarean delivery is very important. Keeping this in mind, this study was performed to assess the effectiveness of pre-caesarean vaginal wash with $5 \%$ Povidone-Iodine solution in reducing infectious morbidity (post operative febrile morbidity and SSI) in cases undergoing cesarean section and to prepare standard operative procedures for our institute regarding the management of caesarean deliveries at institutional level

\section{OBJECTIVES:}

1.To evaluate the efficacy of pre-cesarean vaginal wash using $5 \%$ Povidone Iodine solution on rate of post-cesarean section (CS) surgical site infection (endometrities, febrile morbidity and wound infection) and compared with No swabbing.

2. To Study the side effects of pre-cesarean swabbing with $5 \%$ Povidone Iodine solution.

\section{MATERIAL \& METHODS:}

Study Design-

Prospective Randomized controlled Trial

\section{Sample Size:}

Considering post-caesarean section infectious morbidity rate amongst study group and control group as $9 \%$ and $22.2 \%$ respectively and $95 \%$ CI with $80 \%$ power and using Open Epi sample size calculator, calculated sample size is 164 in each group.

Duration Of Study Period:

$1 / 11 / 2019-30 / 4 / 2020$. 


\section{Inclusion Criteria:}

Pregnant women with a singleton pregnancy undergoing lower segment cesarean section after 28 weeks of gestation \& willing to participate in the study.

\section{Exclusion Criteria:}

Emergent cesarean delivery (umbilical cord prolapse, ante partum hemorrhage), chorioamnionitis, immune compromised status ,cases with intraoperative complications like excessive bleeding, injury to adjacent structures, active genital tract infection, known allergy to 5\% Povidone Iodine solution.

This study was approved by Institution Ethics Committee, Government Medical College \& hospital, Aurangabad. After applying inclusion \& exclusion criteria and after taking written informed consent, women were recruited in study and baseline characteristics were noted. Upon making the decision for caesarean delivery, women were randomly assigned to the control group or interventional group. Upon arrival to operation theatre and after adequate anesthesia, all cases were catheterized with Foley's catheter in sterile manner.

In interventional group, a gauze pieces impregnated with 5\% Povidone Iodine solution was taken with sponge holding forceps and vaginal cleansing was performed from the vaginal apex to the introitus with attention to the anterior, posterior and lateral vaginal wall for at least 30 seconds. After vaginal cleansing, the gloves were changed to perform the abdominal scrub.

The swabbing of vagina was not performed in cases assigned to control group, however the standard surgical preparation of abdomen was done in a usual manner.

The lower segment caesarean section was performed by pfannenstiel by an assistant professor/senior resident on duty in both groups. All women received the antibiotic Inj. Cefotaxime $1 \mathrm{gm}$ intravenous 30 minutes before surgery. All participants received the routine post operative care including antibiotics for 5 days. Maternal demographic details were recorded along with the indication of caesarean section, duration of labour and length of rupture of membranes as well as other surgical parameters. Additionally woman's record were reviewed for the presence of other risk factors like anemia (Hemoglobin $<11 \mathrm{gm} \%$ ) and diabetes mellitus. At the time of hospital discharge length of the hospital stay was recorded and again at 6 weeks post partum, women were followed and data was entered in case record form. Study outcomes included a composite of endometritis, wound infection, or other infections, postoperative maternal fever, length of hospital stay, and the rates of hospital readmission.Post operative febrile morbidity was defined as oral temperature of $38^{\circ} \mathrm{C}$ and greater after first 24 hours of surgery.

Endometritis was defined as post operative fever of $38.4^{\circ} \mathrm{C}$ and greater, with uterine tenderness and foul smelling lochia requiring broad spectrum intravenous antibiotic administration.

Postoperative wound infection was defined as infection at surgical site erythma, tenderness, purulent discharge from incision site, with or without fever, requiring antibiotic therapy.

Postoperative wound seroma or hematoma was defined as collection of serous fluid or blood/clot in the subcutaneous area of the incision that requires parenteral antibiotics and wound care.

Composite wound complications was defined as the presence of any one of the following: wound infection, seroma, hematoma with separation.

\section{Side effects of vaginal preparation (allergy, irritation).}

Women who came with post operative wound infection in outpatient department were readmitted to the hospital for initiation of intravenous antibiotic therapy and wound care. Data were collected from their hospital charts. Measurement bias was minimal because the physician who was evaluating the participant in postoperative period was unaware of any participant's participation in the study. All data was entered and analyzed by using SPSS software version 15 .

Data was analyzed using SPSS software and the $\mathrm{P}$ value $<0.05$ was considered significant.
OBSERVATIONS:

Table1: Baseline Characteristics:

\begin{tabular}{|c|c|c|c|c|c|}
\hline $\begin{array}{l}\text { Sr. } \\
\text { No }\end{array}$ & Parameter & (2) & $\begin{array}{l}\text { Interventio } \\
\text { n group } \\
n=165 \\
(\%) \\
\end{array}$ & \begin{tabular}{|l|} 
Control \\
group \\
$n=165$ \\
$(\%)$ \\
\end{tabular} & P value \\
\hline \multirow[t]{3}{*}{1} & \multirow[t]{3}{*}{ AGE } & $\leq 30$ & $128(77.5)$ & $135(81.9$ & \multirow{3}{*}{\begin{tabular}{|l}
$\mathrm{P}>$ \\
0.05 \\
Chi \\
square \\
value \\
$: 0.9177$
\end{tabular}} \\
\hline & & & & & \\
\hline & & $>30$ & $37(22.2)$ & $30(18.1)$ & \\
\hline \multirow[t]{4}{*}{2} & \multirow[t]{4}{*}{ Gravida } & 1 & 44 (26.6) & $48(29.1)$ & \multirow{4}{*}{$\begin{array}{l}\mathrm{P}= \\
>0.05 \\
\text { Chi } \\
\text { square } \\
\text { value } \\
: 1.191\end{array}$} \\
\hline & & $2-4$ & $118(715)$ & $116(703)$ & \\
\hline & & & & & \\
\hline & & $\geq 5$ & $3(1.9)$ & $1(0.6)$ & \\
\hline \multirow[t]{4}{*}{3} & \multirow[t]{4}{*}{ BMI } & $\leq 18.5$ & 44 (26.6) & $41(24.8)$ & \multirow{4}{*}{$\begin{array}{l}\mathrm{P}= \\
>0.05 \\
\text { Chi } \\
\text { square } \\
\text { value } \\
: 0.522\end{array}$} \\
\hline & & \begin{tabular}{|l|}
$18.5-24.9$ \\
\end{tabular} & $91(55.1)$ & $96(58.2)$ & \\
\hline & & $25-29.9$ & $25(15.1)$ & $22(13.4)$ & \\
\hline & & $>30$ & $5(3.2)$ & $6(3.6)$ & \\
\hline \multirow[t]{5}{*}{4} & \multirow{5}{*}{$\begin{array}{l}\text { Socioeconomic } \\
\text { status }\end{array}$} & Upper class & $1(0.6)$ & 0 & \multirow{5}{*}{$\begin{array}{l}\mathrm{P}= \\
>0.05 \\
\text { Chi } \\
\text { square } \\
\text { value } \\
: 2.215\end{array}$} \\
\hline & & Upper Middle & $20(12.2)$ & $18(10.9)$ & \\
\hline & & Lower middle & $33(20)$ & $27(16.3)$ & \\
\hline & & Upper lower & $37(22.4)$ & $43(26.2)$ & \\
\hline & & Lower class & $74(44.8)$ & 77 (46.6) & \\
\hline \multirow[t]{3}{*}{5} & \multirow{3}{*}{$\begin{array}{l}\text { Gestational age } \\
\text { at C-section }\end{array}$} & $\leq 37$ weeks & $30(18.2)$ & $32(16.4)$ & \multirow{3}{*}{$\begin{array}{l}\mathrm{P}= \\
>0.05 \\
\text { Chi } \\
\text { square } \\
\text { value } \\
: 0.446\end{array}$} \\
\hline & & $>37-40$ weeks & $111(67.2)$ & $113(68.5)$ & \\
\hline & & $>40$ weeks & $24(14.6)$ & $20(12.1)$ & \\
\hline \multirow[t]{4}{*}{6} & \multirow{4}{*}{$\begin{array}{l}\text { Number of } \\
\text { previous c- } \\
\text { section }\end{array}$} & No Lscs & $71(43)$ & $69(41.8)$ & \multirow{4}{*}{$\begin{array}{l}\mathrm{P}= \\
>0.05 \\
\text { Chi } \\
\text { square } \\
\text { value } \\
: 0.309\end{array}$} \\
\hline & & 1 lscs & 57 (34.4) & $60(36.5)$ & \\
\hline & & 2 lscs & $34(20.7)$ & $32(19.3)$ & \\
\hline & & $\geq 3$ lscs & $3(1.9)$ & $4(2.4)$ & \\
\hline \multirow[t]{3}{*}{7} & \multirow[t]{3}{*}{ C section } & Elective & $19(11.5)$ & $16(10.1)$ & \multirow{3}{*}{$\begin{array}{l}\mathrm{P}= \\
>0.05 \\
\text { Chi } \\
\text { square } \\
\text { value } \\
0.2877\end{array}$} \\
\hline & & & & & \\
\hline & & Emergency & $146(88.5)$ & $149(89.9)$ & \\
\hline \multirow[t]{3}{*}{8} & \multirow{3}{*}{$\begin{array}{l}\text { Membrane } \\
\text { Status }\end{array}$} & Intact & $95(57.5)$ & $98(59.3)$ & \multirow{3}{*}{$\begin{array}{l}\mathrm{P}= \\
>0.05 \\
\text { Chi } \\
\text { square } \\
\text { value } \\
: 0.1123\end{array}$} \\
\hline & & & & & \\
\hline & & Ruptured & $70(42.5)$ & $67(40.7)$ & \\
\hline \multirow[t]{4}{*}{9} & Duration of & $\leq 6$ hours & $36(51.4)$ & $34(50.7)$ & $\mathrm{P}=$ \\
\hline & $\mathrm{n}=70$ for cases & $>6-12$ hours & $19(27.1)$ & $18(26.8)$ & Chi \\
\hline & $n=67$ for & $>12-18$ hours & $10(14.3)$ & $11(16.5)$ & square \\
\hline & & $>18$ hours & $5(7.2)$ & $4(6)$ & $: 0.1773$ \\
\hline 10 & Hemoglobin & $<11$ & $19(11.5)$ & $18(10.9)$ & $\mathrm{P}=$ \\
\hline & & & & & \\
\hline & & $\geq 11$ & $146(88.5)$ & $147(89.1)$ & $\begin{array}{l}\text { square } \\
\text { value } \\
: 0.0304\end{array}$ \\
\hline 11 & DM & Present & $1(0.6)$ & $2(1.3)$ & \\
\hline & & Absent & $164(99.4)$ & 163(98.7) & Chi \\
\hline & & Absent & 147 & 146 & $\begin{array}{l}\text { value } \\
: 0.3364\end{array}$ \\
\hline 12 & Number of $\mathrm{P} / \mathrm{v}$ & $\leq 3$ & $135(81.7)$ & $132(80)$ & $\mathrm{P}=>$ \\
\hline & & $4-6$ & $27(16.4)$ & $28(16.9)$ & $\begin{array}{l}0.05 \mathrm{Ch} \\
\text { square }\end{array}$ \\
\hline & & $>6$ & $3(1.9)$ & $5(3.1)$ & $\begin{array}{l}\text { value } \\
: 0.5519\end{array}$ \\
\hline
\end{tabular}


Table 1: shows the baseline data of the 330 women enrolled in the study. The two groups were comparable in age, gravida distribution, BMI. SES, gestational age at the time of LSCS, number of LSCS, emergency/elective LSCS, membrane status, duration of PROM, diabetes, anemia $(\mathrm{Hb}<11 \mathrm{gm} \%)$ and number of $\mathrm{P} / \mathrm{V}$ examinations.

Table 2. Post Operative Complications.

\begin{tabular}{|c|c|c|c|c|}
\hline \multirow[t]{2}{*}{ Fever } & Present & $2(1.2)$ & $9(5.4)$ & \multirow{2}{*}{$\begin{array}{l}\mathrm{P}=0.03289 \\
\text { Chi square } \\
\text { value }: 3.386\end{array}$} \\
\hline & Absent & $163(98.8)$ & $156(94.6)$ & \\
\hline \multirow{2}{*}{$\begin{array}{l}\text { Endome } \\
\text { tritis }\end{array}$} & Present & 0 & 0 & \\
\hline & Absent & 165 & 165 & \\
\hline \multirow{2}{*}{$\begin{array}{l}\text { Wound } \\
\text { Infectio } \\
n\end{array}$} & Present & $2(1.2)$ & $12(7.2)$ & \multirow{2}{*}{$\begin{array}{l}\mathrm{P}=0.0067 \\
\text { Chi square } \\
\text { value : } \\
6.042\end{array}$} \\
\hline & Absent & $163(98.8)$ & $153(92.6)$ & \\
\hline \multirow[t]{2}{*}{ Seroma } & Present & $2(1.2)$ & $3(1.8)$ & \multirow{2}{*}{$\begin{array}{l}\mathrm{P}=0.3261 \\
\text { Chi square } \\
\text { value : } 0.2031\end{array}$} \\
\hline & Absent & $163(98.8)$ & $162(98.2)$ & \\
\hline \multirow{2}{*}{$\begin{array}{l}\text { Compos } \\
\text { ite } \\
\text { wound } \\
\text { infectio } \\
n\end{array}$} & Present & $2(1.2)$ & $3(1.8)$ & \multirow{2}{*}{$\begin{array}{l}\mathrm{P}=0.3261 \\
\text { Chi square } \\
\text { value }: 0.2031\end{array}$} \\
\hline & Absent & $163(98.8)$ & $162(98.2)$ & \\
\hline Hospital & $\leq 7$ days & $158(95.8)$ & $150(90.9)$ & \multirow{2}{*}{$\begin{array}{l}\mathrm{P}=0.03875 \\
\text { Chi square } \\
\text { value: } 3.117\end{array}$} \\
\hline Stay & $>7$ Days & $7(4.2)$ & $15(9.1)$ & \\
\hline $\begin{array}{l}\text { Readmi } \\
\text { ssion }\end{array}$ & Yes & $0(0)$ & $2(1.2)$ & $\begin{array}{l}\mathrm{P}=>0.05 \\
\text { Chi square } \\
\text { value }: 0.503\end{array}$ \\
\hline
\end{tabular}

Table 2 shows the postoperative complications in interventional group and control group. In interventional group fever, wound infection, seroma and composite wound infection $1.2 \%$ each while prolonged hospital stay in $4.2 \%$ cases was observed. No case of endometritis was noted and not a single woman required readmission.

In control group, fever (5.4\%), wound infection (7.2\%), seroma $(1.8 \%)$, composite wound infection(1.8\%) and prolonged hospital stay was seen in $9.1 \%$ cases. Readmission for composite wound infection was required in $1.2 \%$ cases and no cases of endometritis was observed.

Statistically significant difference was noted in interventional group in regards to febrile morbidity, wound infection and hospital stay as compared to control group.

\section{DISCUSSION:}

Despite of giving prophylactic antibiotics and skin cleansing, infectious morbidity still remains an important concern after caesarean section. Vaginal wash with antiseptic solution reduces anaerobic gram positive rod bacteria, gram negative rod bacteria \& some anaerobes and various cocci, particularly enterococci.[8] Use of Povidone Iodine solution for vaginal wash is used to reduce infectious morbidity and mortality after caesarean delivery. This intervention is safe, quick and inexpensive and can be easily performed at the same time of Foley catheter insertion.

The limitation of the study is that the bacterial flora before and after intervention was not studied and the culture report was not included in study.

In present series, there was significant reduction in post-operative fever in intervention group than in control group .Out of 9 women in control group who developed postoperative fever, all women underwent emergency caesarean section and the three women were having PROM. In interventional group fever was noted in 2 women who required emergency LSCS and were having PROM more than 18 hrs.

There was observed significant reduction in the wound infection in interventional group as compared to control group. Out of 12 cases of wound infection in control group, 11 women underwent emergency caesarean section, two women were morbidly obese and 6 were having PROM more than 12 hours. One woman had severe anemia .All women required prolonged hospital stay. observed that there composite wound infection was seen in $1.8 \%$ in control while in $1.2 \%$ in interventional group. This difference was not found statistically significant. All 3 underwent emergency caesarean section. One woman was having prolonged PROM of more than 18 hours and other women was a case of previous caesarean section with dense adhesion and diabetes.

Seroma was seen in 3 women in control group while 2 women in interventional group. Anaemia, prolonged PROM and previous caesarean section are the factors associated with seroma.

In our study, vaginal swabbing with 5\% Povidone Iodine solution has shown a statistically significant reduction in febrile morbidity, wound infection and length of hospital stay. The rate of endometritis, seroma. Composite wound infection and readmission were less in intervention group but the difference was not found to be statistically significant. No case of endometritis was observed in interventional group and control. This difference could be attributed to the research population. The risk factor like anemia, BMI and DM were less while most emergency LSCS were with intact membrane.

There was no complaint of irritation in the vagina after use of 5\% Povidone-Iodine solution.

In a study conducted by Shahneela Memon et al ,post caesarean endometritis was noted in $1 \%$ of case group and $7 \%$ of control group $(p$ value: $<0.03)$. There was no measurable effect seen on development of fever and wound infection. However, statistically significant reduction in overall composite morbidity was seen in women with vaginal cleansing group when compared with the controls. She concluded that preoperative vaginal cleansing with Povidone has reduced post caesarean infectious morbidities ${ }^{[4]}$

Shahnaz Barat et al noted the reduced rates of endometritis in vaginal swabbing group. But the rate was not statistically significant. Also, there was no significant difference in postoperative fever, wound infection between these women with and without preoperative vaginal cleansing with Povidone. This disparity may be due the fact that only pregnant women for elective caesarean section were included in the study ${ }^{[9]}$.

\section{CONCLUSION:}

Pre-caesarean vaginal swabbing with $5 \%$ Povidone iodine for at least 30 seconds causes significant decrease in post operative febrile morbidity along with surgical site infection. It is inexpensive and simple intervention which can also be done in a low resource setting to decrease post operative infections.

\section{REFERENCES:}

1. Guzman MA, Prien SD, Blann DW. Post-cesarean related infection and vaginal preparation with povidone-iodine revisited. Primary Care Update for $\mathrm{OB} / \mathrm{GYNS}$ 2002;9(6):206-9.

2. Smaill FM, Grivell RM. Antibiotic prophylaxis versus no prophylaxis for preventin infection after cesarean section.Cochrane Database of Systematic Reviews 2014, Issue CD007482 pub3

3. Haas DM, Pazouki F, Smith RR, et al. Vaginal cleansing before caesarean delivery to reduce postoperative infectious morbidity: a randomized, controlled trial. Am J Obste Gynecol. 2010; 202: 310.e1-6.PMid:20207251. https://doi.org/10.1016/j.ajog.2010. 01.005

4. Shahneela Memon, Roshan Ara Qazi, Seema Bibi, Naheed Parveen,Effect of preoperative vaginal cleansing with an antiseptic solution to reduce post caesarean infectious morbidity,J Pak Med Assoc,Vol. 61, No. 12, December 2011 1,1179-1183.

5. French LM, Smaill FM. Antibiotic regimens for endometritis after delivery. Cochran Database Syst Rev. 2004; 2. CD001067.https://doi org/10.1002/14651858. CD001067 pub2.

6. Dhanya M, Roger E, Erika O, et al. Antibiotic regimens for postpartum endometritis Cochrane Database of Systematic Reviews. 2015.

7. Shrinivas Gadappa, Honey Gemavat*, Sonali Deshpande, Ankita Shah,Interventions to reduce caesarean section rates at government medical college and hospital Aurangabad, India.International Journal of Reproduction, Cotraception, Obstetrics and Gynaecology 20Apr;9(4):1563-9.www.ijrcog org.

8. Amstey MS, Jones AP. Preparation of the vagina for surgery. A comparison of povidoneiodine and saline solution. Jama. 1981;245(8):839-841.

9. Barat S, Bouzari Z, Ghanbarpour A, Zabihi Z. Impact of preoperative vaginal preparation with povidone iodine on post cesarean infection. Caspian J Reprod Med. 2016;2 (1):1-7 URL: http://caspjrm.ir/article-1-95-en.html 